\title{
The Relationship Between Serum Level of Interleukin-10 and State of the Disease with Atopic Dermatitis and Helminth in Children
}

\author{
Farida Tabri ${ }^{1}$, Mochammad Hatta ${ }^{2,}$, Khaeruddin Djawad $^{1}$, Siswanto Wahab ${ }^{1}$, \\ Ilhamjaya Patellongi ${ }^{3}$ \\ ${ }^{1}$ Department of Dermatology and Venereology, Faculty of Medicine, Hasanuddin University, Makassar, Indonesia \\ ${ }^{2}$ Molecular Biology \& Immunology Laboratory, Faculty of Medicine, Hasanuddin University, Makassar, Indonesia \\ ${ }^{3}$ Department of Biostatistic, Faculty of Public Health, Hasanuddin University, Makassar, Indonesia
}

Email address:

hattaram@indosat.net.id (M. Hatta)

${ }^{*}$ Corresponding author

\section{To cite this article:}

Farida Tabri, Mochammad Hatta, Khaeruddin Djawad, Siswanto Wahab, Ilhamjaya Patellongi. The Relationship Between Serum Level of Interleukin-10 and State of the Disease with Atopic Dermatitis and Helminth in Children. International Journal of Immunology.

Vol. 4, No. 6, 2016, pp. 73-77. doi: 10.11648/j.iji.20160406.15

Received: December 8, 2016; Accepted: December 20, 2016; Published: January 19, 2017

\begin{abstract}
Background: IL-10 is an antiinflammatory cytokine. During infection it inhibits the activity of Th1 cells, NK cells, and macrophages. Regulatory cytokine interleukin-10 (IL-10) has been proposed as a key molecule involved in the attenuation of helminth infection and chronic inflammation, such as atopic dermatitis. The maintenance of the asymptomatic state is now recognized as reflecting an immunoregulatory environment, which may be promoted by parasites, and involves multiple levels of host regulatory cells and cytokines; currently, there is much interest in whether helminth-associated immune regulation may ameliorate allergy and autoimmunity. The objective of this study was to measure the IL-10 level in healthy person, atopic dermatitis, helminth infection and healthy persons. Methods: Levels of IL-10 was measured by ELISA technique. Kato-Katz method is used to determine the number of eggs of helminth. Results: Our study showed that those aged $>5$ years old and helminth infection without atopic dermatitis had higher levels of IL-10 (3.05 \pm 2.44$)$ which was significantly higher $(p<0.001)$ than in children whose atopic dermatitis without the helminth infection $(1.76 \pm 2.72)$. We found that increased levels of IL-10 in helminth infection $(3.05 \pm 2.44)$ higher than healthy subjects $(1.72 \pm 1.74)$; but not statistically significant $(p=0.072)$. The level of IL-10 did not have significant relationship either at age $\leq 5$ years old and $>5$ years old in others group. Also, no correlation between egg count of helminth and level of IL-10 in serum. Conclusion: The serum of IL-10 was significantly higher in children $>5$ years with helminth infection without atopic dermatitis than children with atopic dermatitis.
\end{abstract}

Keywords: Interleukin-10, Atopic dermatitis, Helminth Infection

\section{Introduction}

Interleukin-10 is a key cytokine produced by a multitude of immune effector cells and possesses distrinct regulatory effects on immune functioning in the skin. IL-10 can influence and potentially treat $\mathrm{T} 1 / \mathrm{T} 2$ differentation, antigenpresenting cell functioning, antigen - presenting cellmediated at-cell activation, and T cell, B cell, and mast cell growth and differentiation is abberant in various disease process [1].

Atopic dermatitis $(\mathrm{AD})$ is a chronically relapsing skin disease that occurs most commonly during early infancy and childhood. It is frequently associated with abnormalities in skin barrier function, allergen sensitization, and recurrent skin infections. There is no single distinguishing feature of $\mathrm{AD}$ or a diagnostic laboratory test [1].

Since the 1960s, there has been a more than threefold increase in the prevalence of $\mathrm{AD} . \mathrm{AD}$ is a major public health problem worldwide, with a prevalence in children of $10-20 \%$ 
in the United States, Northern and Western Europe, urban Africa, Japan, Australia, and other industrialized countries [2]. Generally the prevalence of atopic eczema seems to be higher in Australia and Nothern Europe compard to Asia and eastern Europe [2]. The prevalence of $\mathrm{AD}$ in adults is approximately $1-3 \%$. Interestingly, the prevalence of $\mathrm{AD}$ is much lower in agricultural regions of countries such as China and in Eastern Europe, rural Africa, and Central Asia. However, the most recent data from the International Study of Asthma and Allergies in Childhood (ISAAC) Phase Three study confirms that $\mathrm{AD}$ is a disease with high prevalence, affecting patients in both developed and developing countries. There is also a female preponderance for $\mathrm{AD}$, with an overall female/male ratio of 1.3:1.0 [3].

Alergic disease are rarely found in the region with high prevalence. The helminth infection are mostly found in low incidence area, such as urban and industrial area. Based on the research assumed that the helminth infection induces the systemic immunomodulator include $\mathrm{T}$ - cell regulation and Antiinflammatory cytokine, IL-10 which has a important role in protection against allergy phenotypes. Many studies did not support the hypotesis in mast cell maturation and $\operatorname{IgE}$. But some sources assumed that the protection related to interleukin-10 [4].

Soil-transmitted helminths (STH) infects more than 2 billions people worldwide, especially in developing countries located in tropical and subtropical regions. The most prevalent species are Ascaris lumbricoides, Trichuris trichiura, and Ancilostoma duodenale [5]. In addition to health impact, STH infects the human host in more subtle manner, as extracelluler metazoan parasites, helminth trigger type-2 immune response mediated by T-helper type 2(Th2) cells [6]. This response is typicallly characterized by expansion of mast cells [5]. This reponse is typically characterized by expansion of mast cells, eosinophils, basophils, group 2 innate lymphoid cells (ILC-2), and alternatively actived macrophages (AAMs), as well as increased production of Th2 cytokines (e.g., IL-4, IL-5, IL-9, and IL-13) and IgE [7]. Amelioration of the allergic Th2 responses that can accompany helminth infections also depends on the induction of IL-10. IL-10 can directly regulate innate and adaptive $\mathrm{Th} 1$ and $\mathrm{Th} 2$ responses by limiting $\mathrm{T}$ cell activation and differentiation in the lymph nodes as well as suppressing proinflammatory responses in tissues, leading to impaired pathogen control and/or reduced immunopathology [8]. This study to explore the relationship between serum level of IL-10 and stase of disease with atopic dermatitis and helminth infection.

\section{Materials and Methods}

The study was designed with cross sectional method. The study population was patients aged $4 \quad-12$ years in kindergarten and elementary school Makassar City and visiting the Department of Dermatology and Venereology at Wahidin Sudirohusodo Teaching Hospital, Makassar, Indonesia. Patients are grouped as atopic dermatitis and patients who did not suffer atopic dermatitis. After informed consent and parental consent signed the study, parents of participants were asked to answer questions related to the age and history of the disease. Participants diagnosed atopic dermatitis if it meets the William criteria that if there are complaints of itching on the skin and accompanied by at least 3 of the following criteria: 1) the first onset of itching has happened before 2 years old (this criteria is only used in children aged 4 years old or more); 2) history involving itching skin folds such as the folds of the elbows, behind the knees, front legs joints and around the neck (or cheek if children under 2 years old); 3) a history of atopy such as asthma or rhinitis (in children under the age of 4 years); 4) a history of skin dryness in the last year; 5) obvious flexural eczema (including eczema on the cheeks, forehead and outer limbs in children under 4 years old) [1].

Five $\mathrm{ml}$ of blood from each participant was taken to check levels of IL-10 serum. Levels of IL-10 is checked by using a Quantikine ELISA Human IL-10 kit (R\&D system, USA) and was measured by ELISA technique. Stool samples of approximately 1 teaspoon collected from each participant to see whether there is a helminth infection. In this research, we use children with helminth infection only without atopic dermatitis. Kato-Katz method is used to determine the severity of the infection. Severe infections define if in each gram of feces found Ascaris lumbricoides, Trichuris trichiura and Ascaris duodenale eggs respectively 50.000, 10.000 and 4.000; medium infections when the number of $A$. lumbricoides, T. trichiura and A. duodenale eggs each 500049999, 1000-9999, and 2000-3999; and a mild infection if the number of $A$. lumbricoides, T. trichiura, and A. duodenale eggs respectively 4.999, 999 and 999 eggs [9].

\section{Results}

The number of patients who participated in this study were 80 children aged 4 to 12 years old. 47 participants were diagnosed atopic dermatitis and 21 participants were healthy. Helminth infection was found in 12 children with $A$. lumbricoides infect 4 patients, mixed infection of T. trichiura and $A$. duodenale infect 1 patient, A. doudenale infect 2 patients, mixed infections of $A$. lumbricoides and $A$. duodenale was 1 patient and mixed infections of T. trichiura, A. lumbricoides, and $A$. duodenale were 2 patients, and Mixed infection of $A$. lumbricoides and T. trichiura were 2 patients. Levels of IL-10 serum obtained is $1.3-19.05 \mathrm{pg} / \mathrm{ml}$ with an average value $1.95 \mathrm{pg} / \mathrm{ml}$

In table 1 showed that The level of IL-10 of $A$. lumbricoides (egg count 448) and T. trichiura (egg count 21) was found at 5.04, A. lumbricoides (egg count 162) and $T$. trichiura (egg count 4) at 2.34, A. lumbricoides (egg count 139 ) and T. trichiura (egg count 2) at 2.58, A. lumbricoides (eegg count 86) and $T$. trichiura (egg count 2) at 5.10, $A$. lumbricoides (egg count 52) and $A$. duodenale (egg count 9) at 1.30, A. lumbricoides (egg count 51) was found at 1.30, $A$. lumbricoides (egg count 21) was found at 1.30, The level of A. lumbricoides (egg count 4) was found at 9.01, A. 
lumbricoides (egg count 2) was found at 4.76, A. duodenale (egg count 9) was found at1.30, The level of IL-10 of $A$. duodenale (egg count 4 ) was found at 1.30, and The level of
IL-10 (egg count 2) was found at 1.30.

There's no correlation between egg count and the level of IL-10 in serum.

Table 1. The IL-10 Level in Patient with EGG Count of Helminth without Atopic Dermatitis.

\begin{tabular}{|c|c|c|c|c|c|c|c|}
\hline Category & Participant & Gender & Age & Level & A. lumbricoides & T. trichiura & A. duodenale \\
\hline \multirow{10}{*}{$\geq 5$ y. o } & 1 & $\mathrm{M}$ & 7 & 5.04 & 448 & 21 & 0 \\
\hline & 2 & $\mathrm{~F}$ & 9 & 2.34 & 162 & 4 & 9 \\
\hline & 3 & $\mathrm{~F}$ & 9 & 2.58 & 139 & 2 & 4 \\
\hline & 5 & $\mathrm{~F}$ & 11 & 1.30 & 52 & 0 & 9 \\
\hline & 6 & M & 12 & 1.30 & 51 & 0 & 0 \\
\hline & 7 & M & 11 & 1.30 & 21 & 0 & 0 \\
\hline & 9 & M & 8 & 4.76 & 2 & 0 & 0 \\
\hline & 10 & M & 10 & 1.30 & 0 & 0 & 9 \\
\hline & 11 & $\mathrm{~F}$ & 11 & 1.30 & 0 & 4 & 4 \\
\hline & 12 & $\mathrm{~F}$ & 11 & 1.30 & 0 & 0 & 2 \\
\hline
\end{tabular}

Table 2. Relationship between The Serum level of IL-10 and state of disease.

\begin{tabular}{|c|c|c|c|c|}
\hline No & State of disease & Total Patient (n) & Mean \pm SD soluble IL-10 $(\mathrm{pg} / \mathrm{ml})$ & Significancy \\
\hline & Atopic dermatitis & & & \\
\hline \multirow[t]{3}{*}{1} & Age $\leq 5$ years old & 4 & $1.19 \pm 1.78$ & $\mathrm{P}^{*}=0.519$ \\
\hline & Age $>5$ years old & 43 & $1.76 \pm 2.72$ & \\
\hline & Helminth infection & & & \\
\hline \multirow[t]{3}{*}{2} & Age $\leq 5$ years old & 0 & - & - \\
\hline & Age $>5$ years old & 12 & $3.05 \pm 2.44$ & \\
\hline & Healthy & & & \\
\hline \multirow[t]{3}{*}{3} & Age $\leq 5$ years old & 3 & $1.30 \pm 0.00$ & $\mathrm{P}^{*}=0.814$ \\
\hline & Age $>5$ years old & 18 & $1.72 \pm 1.74$ & \\
\hline & Age $\leq 5$ years old & & & \\
\hline \multirow[t]{3}{*}{4} & Atopic dermatitis & 4 & $2.19 \pm 1.78$ & $P^{*}=0.629$ \\
\hline & Healthy & 3 & $1.30 \pm 0.00$ & \\
\hline & Age $>5$ years old & & & \\
\hline \multirow[t]{3}{*}{5} & Atopic dermatitis & 43 & $1.76 \pm 2.72$ & $\mathrm{P}^{*}<0.001$ \\
\hline & Helminth & 12 & $3.05 \pm 2.44$ & \\
\hline & Age $>5$ years old & & & \\
\hline \multirow[t]{3}{*}{6} & Atopic dermatitis & 43 & $1.76 \pm 2.72$ & $P^{*}=0.376$ \\
\hline & Healthy & 18 & $1.72 \pm 1.74$ & \\
\hline & Age $>5$ years old & & & \\
\hline \multirow[t]{2}{*}{7} & Helminth & 12 & $3.05 \pm 2.44$ & $P^{*}=0.072$ \\
\hline & Healthy & 18 & 1.74 & \\
\hline *Th & nn Whitney U test & & & \\
\hline
\end{tabular}

From the table above it can be seen that those aged $\leq 5$ years old with atopic dermatitis had higher levels of IL-10 (2.19 \pm $1.78)$ than the healthy group $(1.30 \pm 0.00)$ but not significantly $(p=0.629)$. Those aged $>5$ years old with atopic dermatitis had lower levels of IL-10 $(1.76 \pm 2.72)$ than with the healthy group $(1.72 \pm 1.74)$ but not significantly $(p=0.376)$. And those aged $>5$ years old with helminth infection had higher levels of IL-10 $(3.05 \pm 2.44)$ than with the healthy group $(1.72 \pm 1.74)$ but still not significantly $(\mathrm{p}=0.072)$. And it can be seen that those aged $>5$ years old and helminth infection without atopic dermatitis had higher levels of IL-10 $(3.05 \pm 2.44)$ which was significantly higher $(\mathrm{p}<0.001)$ than in children whose atopic dermatitis without the helminth infection $(1.76 \pm 2.72)$.

\section{Discussion}

It is evident that IL-10 can be produced by many different myeloid and lymphoid cells and that more than one population of IL-10 producing cells may be induced during a single infection [10]. In consequence, IL-10 can both impede pathogen clearance and ameliorate immunopathology [11]. Many different types of cells can produce IL-10, with the major source of IL-10 varying in different tissues or during acute or chronic stages of the same infection. The priming of these various IL-10 producing populations during infections is not well understood and it is not clear whether the cellular source of IL-10 during infection dictates its cellular target and thus its outcome. In this article we review the biology of IL-10, its cellular sources, and its role in helminth, viral, bacterial, and protozoal infections [12].

IL-10 can act directly on CD-4 T-cells, inhibiting proliferation and production of IL-2, IFN- $\alpha$, IL-4, IL-5 and TNF- $\alpha$ [13]. However, IL-10 can directly regulate innate and adaptive Th1 and Th2 responses by limiting $\mathrm{T}$ cell activation and differentiation in the lymph nodes as well as suppressing proinflammatory responses in tissues, leading to impaired pathogen control and reduced immunopathology (14). IL-10 inhibits the synthesis of 
several cytokines that are normally secreted by human and mouse monocytes/macrophages in response to activation by lipopolysaccharide.

The suspected key players for infection-mediated immune suppression of autoimmunity and atopy are T-regulatory cells and dendritic cells, which produce immunosuppressive cytokines, such as interleukin-10 and transforming growth factor- $\beta$. However, there is also solid evidence suggesting that infections can exacerbate or even directly cause autoimmune and allergic disorders.

Atopic dermatitis, which is synonymous with atopic dermatitis, is a difficult condition to define robustly because it lacks a diagnostic test and shows variable clinical features. The following definition seems to be in accord with most consensus groups: $\mathrm{AD}$ is an itchy, chronic or chronically relapsing inflammatory skin condition that often starts in early childhood (usually before 2 years of age) (2). The rash is characterized by erythema, itchy papules/papulovesicles (occasionally vesicles in infants) which may become excoriated and lichenified, and typically has a flexural distribution. The eruption is frequently associated with other atopic conditions in the individual or other family members.

In this study proposed major and minor diagnostic criteria based on their clinical experience. These criteria allow a uniformity of diagnosis for hospital-based and experimental studies but were considered not helpful for population-based studies (3). Consequently, Williams et al. coordinated the United Kingdom working party to attempt to refine the criteria of Hanifin and Rajka into a repeatable and validated set of diagnostic criteria for AD which were shown to have an $80 \%$ positive predictive value and $97 \%$ negative predictive value [14]. These diagnostic guidelines appear to be valid for adults, children and non-white ethnic groups suffering from $\mathrm{AD}$, and have been validated in a population setting (16). They were primarily developed for epidemiological studies and, of necessity, exclude some signs that could be useful for diagnosis in individuals but are not common enough for use when assessing large populations. More recently, other modifications of the diagnostic criteria have been proposed, but these have been less rigorously validated [4].

Our study showed that those aged $>5$ years old and helminth infection without atopic dermatitis had higher levels of IL-10 (3.05 \pm 2.44$)$ which was significantly higher ( $p$ $<0.001)$ than in children whose atopic dermatitis without the helminth infection $(1.76 \pm 2.72)$.

IL-10 correlated with helminth infection. but, the egg count did not affect the level of IL-10 in serum.

A cross-sectional study of 96 Nigerian school children with or without A. lumbricoides infection measured IL-10 serum levels by an unspecified enzyme-linked immunosorbent assay (ELISA) (15). This study showed that children with ascariasis had significantly higher IL-10 serum concentrations than non-infected controls [16]. High levels of IL- 10 are produced during helminth infection and the ability of IL -10 to down- modulate the allergic response is well documented [17]. However, both allergic and helminth infection produce complex changes in the immune system, and it is likely that other mediators participate in the different steps leading to a down - regulation of the immune response caused by helminth infection [18].

Increased production of anti-inflammatory cytokines, especially IL-10 on helminth infection plays an important role in controlling allergies [19]. Based on one study, children are infected by helminth had high level of IL-10 and can reduce skin reactions to dust allergens [20]. In addition, they also have high levels of schistosome antigens with specific concentrations of the IL-10 and high concentration of IL-10 have negative skin reaction effects to house dust. It confirms that the effect of $\operatorname{IgE}$ on the skin test is suppressed by a parasite worm [21]

\section{Conclusion}

In conclusion, we found that IL-10 production was associated with helminth infection. There is no correlation between the egg count and IL-10 level. Therefore, we can conclude that the increase of IL-10 level primarily correlated with inflammation caused by helminth parasites.

\section{References}

[1] Goldsmith L, Kats Z, Gilchrest B, Paller A, Leffel D, Wolf K. Fitzpatrick's Dermatology in General Medicine. 8th edition. United States: The McGraw-Hill Companies, 2012.

[2] Griffiths C, Barker J, Bleiker Tanya, Chalmers R. Atopic dermatitis. Rook's Textbook of Dermatology $9^{\text {th }}$ edition. Oxford: Wiley Blackwell Publishing, 2016.

[3] R. Johannes, Hanifin J. Atopic Dermatitis. Baravia, Germany: Spinger International Publishing, 2016.

[4] Bethony J, Brooker S, Albico M, Geiger SM, Loukas A, Diemert D, et al. Soil-transmitted Helminth infections: Ascariasis, trichuriasis, and Hookworm. Lancet, 2006; 367: 1521-32.

[5] Hu. X, Lionel B. Ivashkiv. Cross Regulation of Signalling and Immune Responses by IFN $\gamma$ and STAT1. Immunity, 2009;31 (4): $539-550$.

[6] Saraiva M, Christensen JR, Veldhoen M, Murphy TL, Murphy $\mathrm{KM}$, et al. Interleukin-10 production by Th1 cells requires interleukin -12 induced STAT4 transcription factor and ERK MAP kinase activation by high antigen dose. Immunity, 2009; 209-219.

[7] Kamradt, T., Goggel, R., \& Erb, K. Induction, exacerbation and inhibition of allergic and autoimmune diseases by infection. Trends in Immunology, 2006; 26 (5): 260-267.

[8] Flohr, C. Quinell, R. \& Britton, K. Do Helminth parasites protect against atopy and allergic disease? Clinical Exp Allergy, 2009; 39: 20-32.

[9] Rusmartini, The examination technic for parasitic worm in Natadisastra, D \& Agoes, R. (Eds.). Jakarta: EGC medical book publishing, 2009. 
[10] Van Riet, Hager, F. \& Yazdanbakhsh, M. Chronic helminth infections induce immunomodulation: Consequences and mechanisms. Immunology, 2007; 212: 475-90.

[11] Mosman, Tim R. "Properties and Functions of Interleukin-10." Advances in Immunology, 2005: 56; 1-26.

[12] Anthony, R., Rutitzky, L., J., Stadecker, M. \& Gause, W. Protective immune mechanisms in Helminth Infection. Nat Rev Immunol, 2007: 975-87.

[13] Kluken, H., Wienker, T. \& Beiber, T. 2003 Atopic Eczema / dermatitis syndrom genetivally complex disease. New advances in discovering the genetic contribution. Allergy, 2003; 58: 5-12.

[14] Zdanov, A. structure and function of IL-10 and IL-10 receptor. dalam Marincola, F. (Ed). Interleukin -10. Texas, Landes Bioscience, 2006.

[15] Gooddey NOP, Osagie ID, Maliki A. Serum cytokines profiles in Nigerian children with Ascaris lumbricoides infection. Asian Pac J Trop Med, 2010; 3: 288-91.

[16] Bieber T: Atopic dermatitis. N Engl J Med 358, 2008: 1483.
[17] Carvalho EM, Bastos LS, Araujo MI. Worms And Allergy. Parasite Immunol, 2006; 28: 25-534. PIM894 [Pii]. PMID: 16965288.

[18] Cooper PJ, Chico ME, Rodriques LC, Ordonez M, Strachan, $\mathrm{D}$, et al. Reduced risk of atopy among school- age children infected with geohelminth parasites in a rural area of the tropics. J Allergy Clin Immunol, 2005; 111: 995-1000.

[19] Stein M, Weismann Z, Handzel Z, Bentwich Z. Allergy and Helminthic Infections in Ethiopian immigrants to israel increased atopy following parasites eradication? J Allergy Clin Immunol, 2004; 105[1]: S 302

[20] Mehta RS, Rodriques A, Chico M, Guadalupe 1, Broncano N, Sandoval C, et al. Maternal geohelminth infections in children: A case- control study. Plos Neql Trop Dis, 2012; 6: e1753.

[21] Faulkner H, Turner J, Kamqno J, pion SD, Boussinesq M, Bradley JE. Age- and infection intensity-dependent cytokine and antibody production in human trichuriasis: the importance of IgE. J infect Dis, 2002; 185: 665-72. 